\title{
Investigation of indoor environment quality in the storage areas of NTNU Gunnerus Library
}

\begin{abstract}
The NTNU Gunnerus Library is one of the most important cultural heritage libraries in the Nordic countries. The collections consist of a combination of materials with different levels of instabilities. In view of this fact, the target condition needs to be a compromise in order to maintain the required indoor environmental quality for the storage area. There are a number of consequences as a result of inadequate conditions of relative humidity, air temperature and air distribution. The main categories of degradation are biological, mechanical and chemical degradation. Literature states, that to minimize degradation of the cultural material stored at the library, it is important to maintain stable thermo-hygrometric values. The analysis of the measurements indicates a wide range of thermo-hygrometric values to which the storage area is exposed. Thus, the comfort zone, which is determined by the optimal condition including seasonal- and short-time fluctuation range, is often exceeded and the content of the storage is exposed to a substantial threat of damage.
\end{abstract}

\section{The NTNU Gunnerus Library}

The NTNU Gunnerus library, located in Trondheim, Norway, is one of the most important cultural heritage libraries in the Nordic countries, and has since the late 18th century regularly received gifts and bought collections of literature. The storage areas house a large collection of Norwegian, Nordic and European works of fiction and non-fiction dating back to the 16th and 17th centuries. To name a few, original manuscripts written by historic Norwegian figures such as Henrik Wergeland and Bjørnstjerne Bjørnson are stored at the storage areas at Gunnerus library. [1]

\subsection{Description of the storage areas}

The special collections are held in four storage areas, on four separate floors, floor 7 to floor 10. Each area measure approx. $200 \mathrm{~m}^{2}$, with a ceiling height of $2,15 \mathrm{~m}$, and thereby an approx. room volume of $430 \mathrm{~m}^{3}$ The division of shelving is more or less the same for the 4 areas.

In general, the shelves run from floor to ceiling and primarily consist of two types; an older structure, which also has a load-bearing function, and a newer shelving structure. It appears after close observation of the shelves that the older structure over time has been affected by humidity and is slowly degrading. The new structure shows no signs of degradation.

Repetitive in all of the storage areas are shelves packed to its full capacity. At some locations in the storage areas, the artefacts are in very close or in direct contact with the internal walls or ceiling. The limitation in space and structure of the shelves prevents proper airflow through the area.

\subsection{HVAC system}

All of the four storage areas share one climate regulation system, which was installed in the 1980s. The system uses re-circulated air and allows for heating/cooling of the storage areas. To achieve a slight over-pressure in the areas, the re-circulated air is mixed with a small amount of fresh air supplied from the main system. The system has a set point temperature of $18{ }^{\circ} \mathrm{C}$ and if the temperature is too low, the heating coil will heat the temperature of the supply air. Conditions where the temperature is too high, individual cooling systems will start.

Each of the storage areas has only one supply air inlet, which is located on the wall in the middle of the room. There are four exhaust air outlets on the right side of the room. In addition to this, there is an individual cooling and dehumidifier system, placed in each storage area.

Fire- and water leakage represents a big risk of damaging the content of the storage areas. Therefore, there are no water- or steam pipes in the storage areas. Previously there were radiators to provide heat, but they are now disconnected as a result of the mentioned risk factor. 


\section{Field measurement at the NTNU Gunnerus Library}

Field measurements of the climatic changes were conducted at two out of four storage areas at NTNU Gunnerus library, floor 8 and floor 10. This included measurements of relative humidity and temperature. These parameters are the major factors affecting the longevity of paper-based collections and are the chosen parameters to be measured.

The product type of the sensors used in the measurements is called Tinytag Plus 2, which is designed to for measuring climatic changes in temperature and relative humidity in a variety of environments. [2]

Four Tinytag sensors were placed in each area. The placement selected for the four meters was chosen to represent the environment in order to detect any differences throughout the area.

In addition, measurements from the already existing sensors placed by the paper and book conservator Victoria Juhlin was also utilized in order to se changes in the environment over a longer time period.

Figure 1 illustrates the placement of the sensors A-D and $1-4$, respectively the newly placed sensors and the longterm sensors.

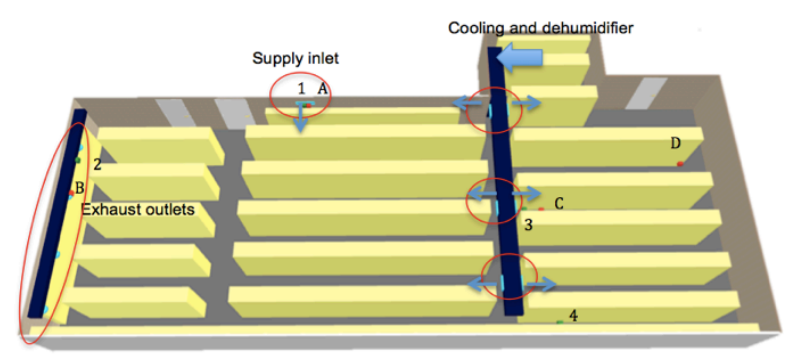

Fig. 1. Placement of sensors

\section{Consequences of inadequate environment for the content in the storage}

Inadequate indoor conditions of relative humidity, temperature and air distribution may cause damage of different kind and scale on historical artefacts. Traditionally these concerns have led to narrow specifications for guidelines for museums, archives and libraries. The main categories of degradation are biological, mechanical and chemical degradation. For optimal preservation of paper-based material, it is beneficial to minimize the biological, mechanical and chemical stress on the content of the archive, by maintaining relatively low and stable values of air temperature and relative humidity. [3, 4]

\section{Results and discussion}

This chapter presents the result and discussion of this study. Firstly it is given a comparison of the environment of the different floors and the different locations inside the storage area. The measurement data of temperature and relative humidity are analysed and evaluated against standards and guidelines given in this paper. Both shortterm and seasonal fluctuation requirements are evaluated.

\subsection{Comparison of the environment inside the storage}

Due to the rectangular shape of the storage area and the limited amount of supply air inlets, there are reasons to assume that the indoor environment varies throughout the area. This section compares the measurements from meter $\mathrm{B}$ and $\mathrm{D}$ in floor 8 , respectively located at the exhaust outlet and at the wall on the other side of the area.

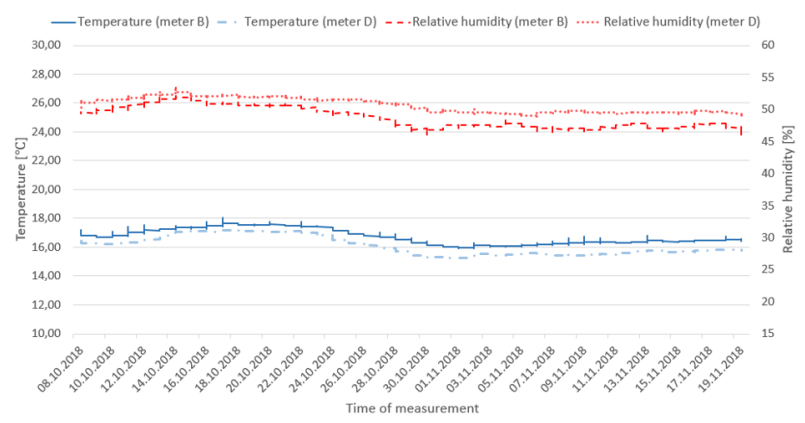

Fig. 2. Comparison of temperature and relative humidity measurements from meter B and D

The given result suggests that the assumption of a varying environment in the area is correct, and that measurements conducted by the "NTNU Technical Management section" of the exhaust air in each floor, will either underestimate or overestimate the climate condition in the total area.

\subsection{Comparison of the environment of floor 8 and 10}

The storage areas share one climate regulation system. The cooling and dehumidifier, on the other hand, are separated. In view of the fact that they share the same ventilation system for air-circulation and heating by the supply air, it is interesting to compare the environment of the floors to display any differences. The comparison is made by the measured values by meter $\mathrm{B}$ in floor 8 and 10 . 


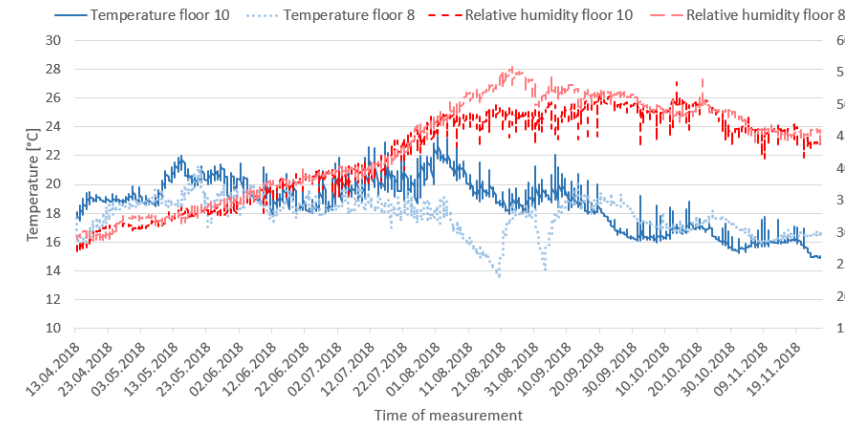

Fig. 3. Comparison of the environment in floor 8 and 10, meter B

Figure 3 displays that the conditions for both temperature and relative humidity vary for the different floors. Varying values for the different floors will make it problematic to meet the demand and requirements of each floor.

\subsection{Analysis in comparison to standards and guidelines}

Due to the unspecific nature of the different guidelines and standards, there are no exact values to follow for either set-points or fluctuations values for temperature and relative humidity. Recurring for the standards and guidelines is the importance to maintain stable conditions for both temperature and relative humidity. However, a prerequisite is that every storage environment is different and most of all dependent on the content in the storage. Therefore, it is desirable that the set-point values for the storage environment are evaluated and decided in collaboration of expertise and in-house knowledge.

According to Victoria Juhlin and Stein Olle Johansen, respectively the paper- and book conservator and head of department at the NTNU Gunnerus Library, the desired climate condition to maintain in the storage area is $50 \%$ relative humidity and $19^{\circ} \mathrm{C}$ air temperature.

Taken the cold climate in Trondheim and the environmental aspect into consideration, class of control A given by ASHRAE is the chosen specification for the fluctuations evaluated in this paper. The requirements for set-points and fluctuations used in further analysis are presented in table 1. [3]
Table 1. Requirements for system set-points and fluctuation limits

\begin{tabular}{l|lll} 
Condition & Set-point & $\begin{array}{l}\text { Short-term } \\
\text { fluctuation }\end{array}$ & $\begin{array}{l}\text { Seasonal } \\
\text { fluctuation }\end{array}$ \\
\hline $\begin{array}{l}\text { Relative } \\
\text { humidity }\end{array}$ & $50 \%$ & $\pm 5 \%$ & $\pm 10 \%$ \\
$\begin{array}{l}\text { Temperature } \\
\end{array}$ & $19^{\circ} \mathrm{C}$ & $\pm 2{ }^{\circ} \mathrm{C}$ & $\pm 5^{\circ} \mathrm{C}$
\end{tabular}

\section{Analysis of seasonal fluctuations}

This section presents analysis of the measurements of temperature and relative humidity by meter 1-4 in floor 10. The measurements are evaluated up against the seasonal fluctuation range presented in table 1 .

\section{Temperature}

Figure 4 presents the temperature readings for meter 1-4 at floor 10 with the corresponding set-point temperature and seasonal fluctuation range of $19 \pm 5^{\circ} \mathrm{C}$.

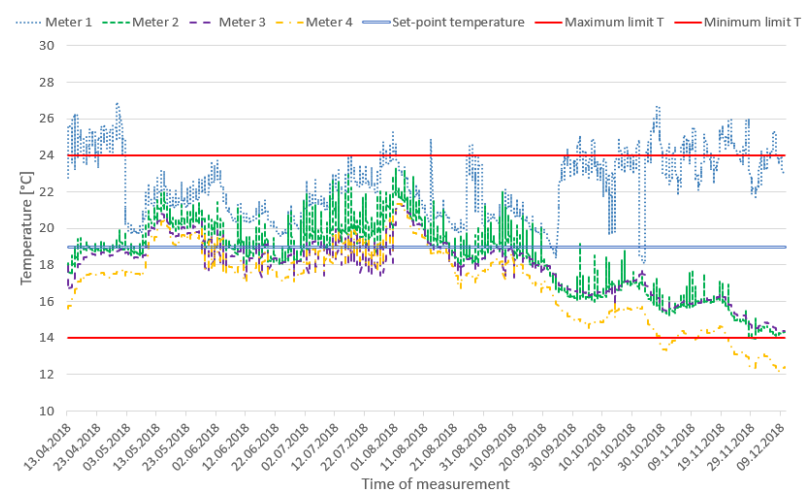

Fig. 4. Temperature readings for meter 1-4 at floor 10, longterm

The overall impression of the graph is that the temperature out of most times stays within the fluctuation range. However, the graph emerges that the outdoor environment affects the temperature to some extent by following a seasonal pattern. The readings show fluctuations at a steadily higher level in the summertime, while in the wintertime there is an evident decrease in temperature in the storage areas.

The readings representing meter 1 , however, show a different trend. Meter 1 measures the temperature of the supply air and controls the temperature in the storage area. As the supply air controls the temperature of the 
storage area, it is a natural consequence that the readings for meter 1 lies at a higher value during the cold seasons. The temperature is repeatedly exceeding the fluctuation range during the cold seasons.

In periods where the temperature is too high, the cooling and dehumidifier system is turned on. This is evident by evaluating the recurring heavy fluctuations on the graph during the months from June to August.

It is also worth noticing the readings representing meter 4 , which is located in direct contact with the external wall. The readings are at a noticeable lower value than for the other meters, which could be related to the influence of the outdoors. The difference appears more evident as the outside temperature decreases, meaning from September until December. Furthermore, the temperature is out of range in the last weeks of the measurement period. As a consequence, the content of the storage area is at risk for damage.

\section{Relative humidity}

Figure 5 presents the measurements of relative humidity by meter $1-4$ at floor 10 , with the corresponding setpoint value and seasonal fluctuation range of $50 \pm 10 \%$.

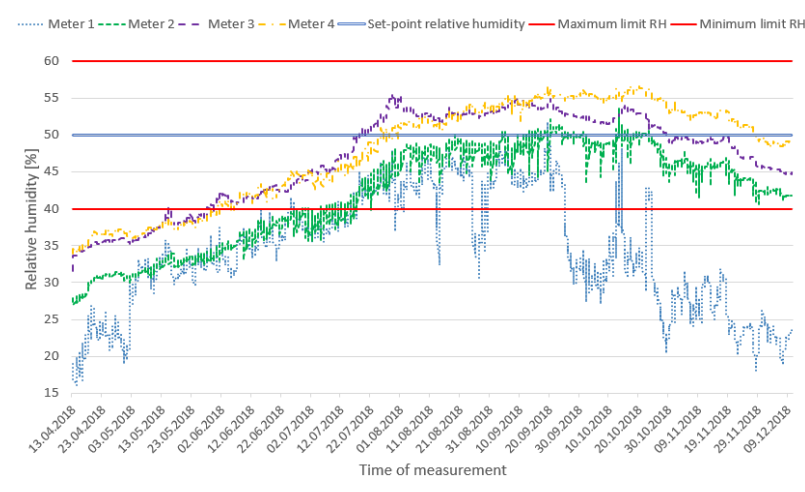

Fig. 5. Relative humidity readings for meter $1-4$ at floor 10 , long-term

First and foremost, the relative humidity is dependent on the temperature of the air. In addition, the humidity in a room varies when humidity is either supplied or extracted from the air. Regarding the storage areas at Gunnerus Library, there are humidity through the envelope and the dehumidifier associated with the cooling system that have an effect on the humidity level. Moreover, the presence of the staff will also play a roll in the matter of humidity increase. Considering that the frequency of visits is assumed to be limited, and not accounted for, it is hard to draw any conclusions based on the visits of the storage areas.

Figure 5 displays substantial variations in the state of the air, with a maximum measured value above $55 \%$ and minimum measured value below $30 \%$. It emerges from the graph that the relative humidity for all meters is too low and out of range from the beginning of the measuring period until June. In association with this condition, the content of the storage area is at risk of degradation associated with low humidity.

Recurring from figure 4 is the deviant trend for meter 1 . The fluctuations of relative humidity are at most times corresponding in opposite direction from the temperature graph, meaning that a decrease in temperature leads to an increase in relative humidity. Therefore, the low relative humidity in figure 5 grounds in the rather high temperature readings displayed in figure 4 Out of most times, except a period during the summer, the state of the air of the supply air is below the minimum limit of $40 \%$ relative humidity.

In the late months of summer, the readings for meter 2-4 are more or less stabilized, followed by an evident decreasing trend as the cold period occurs. As pointed out in the analysis of the temperatures, there is a noticeable difference in the trend for the meter placed directly on the external wall. The graph representing meter 4 shows the relative humidity level is following the same trend of decreasing, although at a higher level compared to the other meters. The higher level of humidity is in correlation with the rather lower temperature in figure 4 and can be seen in the context of external influence.

\section{Analysis of short-term fluctuations}

Fluctuations of thermodynamic parameters over short periods may result in swelling, tearing and other structural degeneration of materials and are assumed to represent a great risk historic content in storage areas. In this section, the measurements of temperature and relative humidity from meter A-D in floor 10 are evaluated against the short-term fluctuation range given in table 1

Figure 6 and 7 shows the fluctuations of temperature and relative humidity over a time period of 24 hours. Based on the result presented and analysed in figure 4 and 5 in the previous sections, October 14th is the chosen date to evaluate the short-term fluctuations.

\section{Temperature}

Figure 6 presents the temperature measurements by meter A-D at floor 10, with the corresponding set-point value and short-term fluctuation range for temperature of $19 \pm 2{ }^{\circ} \mathrm{C}$. 


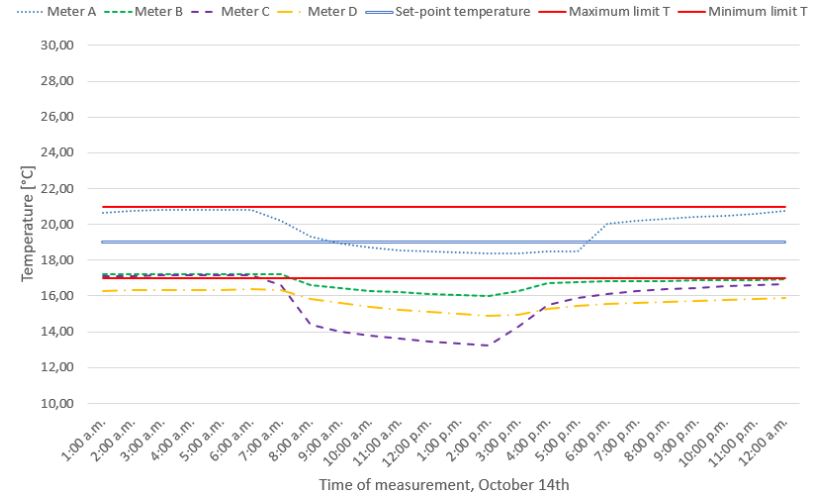

Fig. 6. Temperature readings for meter A-D at floor 10, shortterm

It emerges from the graph that all meters show a drop in temperature between 8 am and $4 \mathrm{pm}$. An explanation for this drop may be that the cooling system was operating. The graph representing meter $\mathrm{C}$ shows the most evident drop. This substantiates the explanation further, due to the location of the meter. Meter $\mathrm{C}$ is located close to the cooling inlet and will, therefore, be directly affected by the cooled air stream.

In view of the detection that the cooling system possibly was operating despite a temperature level within the lower part of the temperature range, indicates that the system may not be optimally managed.

Another possible explanation of the sudden drop is that it was caused by an error in the system making the ventilation system, which regulates heat through the supply air, not operating. This is substantiated by the graph showing a decreasing temperature for the sensor placed in the supply inlet, meter A.

The readings representing meter $\mathrm{D}$ displays a temperature level out of the range of $19 \pm 2{ }^{\circ} \mathrm{C}$ through the entire period. Meter A, however, stays within the range for the whole period but does also experience a drop in temperature between 8 am to $4 \mathrm{pm}$.

\section{Relative humidity}

Figure 7 presents the relative humidity measurements by meter A-D at floor 10, with the corresponding set-point value and short-term fluctuation range for relative humidity of $50 \pm 5 \%$.

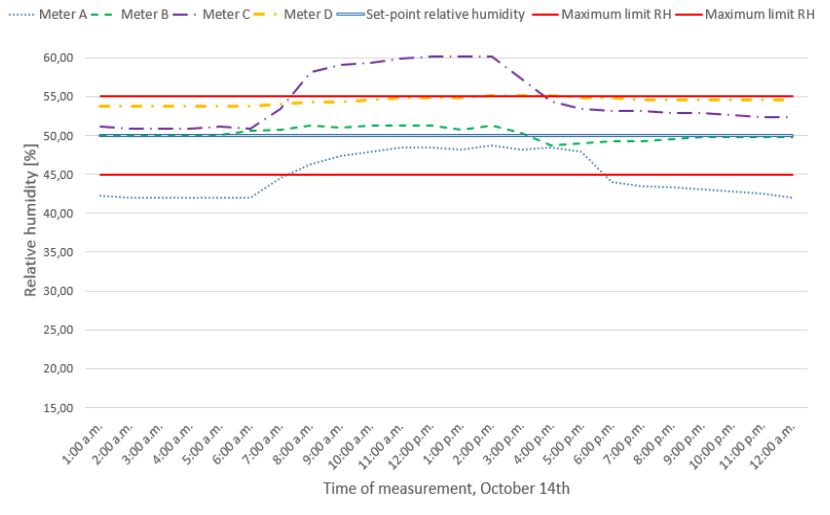

Fig. 7. Relative humidity readings for meter A-D at floor 10, short-term

Firstly, by comparing figure 6 and 7 it becomes evident that the sudden drop in temperature from 8 am to $4 \mathrm{pm}$ leads to a corresponding increase in relative humidity. As enlightened from figure 7 , the most evident increases are to be seen in meter $\mathrm{A}$ and in meter $\mathrm{C}$, which is respectively the meter located close to the supply air inlet and the meter located close to the cooling inlet. The readings for meter $\mathrm{A}$, the supply air, emerge to be out of range in the period before and after the drop. Meter $\mathrm{C}$ shows an opposite effect, by being out of range during the

drop.

\section{Conclusion}

NTNU Gunnerus Library is one of the most important cultural heritage libraries in the Nordic countries and houses collections and artefacts of great value and importance. Most of the content consists of a combination of materials with different levels of instability. Thus, the target condition for the storage areas needs to be a compromise and has proven to be challenging to meet with the current climate regulation system.

In order to survey the indoor environment in the storage areas, sensors measuring temperature and relative humidity were placed in two of the four storage areas. The indoor environment measured by the sensors in floor 8 and 10 was compared as they share the same climate regulation system. The result emerged a varying environment for different floors. A comparison was also made of the environment inside the storage area, detecting a varying environment throughout the area.

Further, by evaluating the relationship between the temperature and the relative humidity it is discovered that they do not always correspond. This signifies that humidity is either added or subtracted the storage area during the measurement period. 
Analysis of the result of both the seasonal- and the shortterm fluctuations indicates a wide range of thermohygrometric values to which the storage area is exposed. Thus, the environment is often outside the comfort zone representing the condition considered safe in order to avoid damage of the artefacts in the storage.

The result of the short-term fluctuation for October 14th showed a deviant drop and increase in temperature and relative humidity, which most likely is related to system failure. Thus, the climate regulation system appears unreliable to maintain the conditions required. In addition, the analysis of the seasonal fluctuations refers to thermo-hygrometric parameters that clearly follow seasonal patterns, which means that they are strongly dependent on the outside environment.

Literature states, that to minimize degradation of the cultural material stored in archives it is important to maintain stable thermo-hygrometric values. The result gathered in this paper indicates that the climate regulation system at NTNU Gunnerus Library does not achieve the indoor environmental quality that is required to meet the requirements for adequate storage conditions.

\section{References}

1. NTNU, Special collections (2018)

2. Geminidataloggers, Tinytag (2018)

3. ASHRAE reaserch, HVAC applications, chapter 23 (2015)

4. P.E Nilsson, Achieving the desired indoor climate, chapter 8 (2003) 